\title{
Psicologia e racismo institucional na saúde pública de Salvador- Bahia
}

\author{
Kaike Costa Oliveira de Jesus, (D) * Hellen Maciel Santana, (D) Marilda Castelar (D) \\ Escola Bahiana de Medicina e Saúde Pública, Salvador, BA, Brasil
}

\begin{abstract}
Resumo
A pesquisa trata da atuação de psicólogas/os em políticas públicas em quatro unidades de saúde em Salvador-Bahia. Objetiva identificar a existência de práticas no combate ao racismo institucional. O estudo é de caráter qualitativo, contemplou sete entrevistas gravadas em áudio, com roteiros semiestruturados. Após transcrição, foram realizadas análises de conteúdo articuladas com estudos sobre racismo institucional e políticas públicas. Os relatos possibilitaram identificar a inexistência de práticas específicas de enfrentamento ao racismo institucional e revelam a necessidade de investimento na discussão das relações raciais e de desenvolver o senso crítico entre os profissionais da área da saúde sobre o racismo. Reafirma-se, assim, a importância da psicologia para a construção do compromisso social e legitimação dos direitos dos cidadãos. Apesar da existência oficial do programa de combate ao racismo institucional no SUS, o tema continua sem visibilidade na formação e prática da psicologia.
\end{abstract}

Palavras-chave: racismo institucional; políticas públicas; psicologia; saúde pública.

\section{Psychology and institutional racism at public health of Salvador- Bahia}

\begin{abstract}
This research deals with the role of psychologists in public policy in four health units in Salvador, Bahia. It aims at identifying the existence of practices that fight against institutional racism. The study is qualitative, with seven audio-recorded interviews with semi-structured scripts. After transcription, content analysis articulated with studies on institutional racism and public policies in the socio-historical perspective was carried out. It was possible to identify the absence of specific practices to fight against institutional racism and to reveal the need for investing in the discussion of race relations aiming at developing critical thinking among health professionals about racism. Thus, the importance of psychology for the construction of social commitment and legitimacy of citizens' rights is reassured. Despite the official existence of the program to fight against institutional racism in SUS, the issue continues without visibility in psychology training and practice.
\end{abstract}

Keywords: institutional racism; public policy; psychology; public health.

\section{Introdução}

O presente estudo contempla um recorte da atuação de profissionais da psicologia, considerando as concepções sobre racismo institucional e fragilidades observadas na formação e prática das profissionais da saúde pública de Salvador. Para tanto, levou-se em consideração os discursos das entrevistadas. Objetiva, também, conhecer as fragilidades vivenciadas por psicólogas/os em seu exercício profissional, buscando identificar a existência de práticas no combate ao racismo institucional.

A escuta diferenciada, um olhar crítico, as análises contextualizadas e o domínio das técnicas pressupõem que sejam ferramentas indissociáveis da prática e do viver de qualquer psicóloga $/ \mathrm{o}^{1}$ advinda/o dos conflitos em sociedade. Este artigo proporciona uma reflexão sobre a atuação de profissionais de psicologia frente às políticas públicas, em quatro Unidades de Saúde de Salvador-Bahia, tendo em vista que, nesse espaço, as/os profissionais de psicologia podem atuar como agentes de transformação da realidade social. Não obstante isso, procurou-se identificar a aproximação de profissionais de psicologia com as relações raciais, mais especificamente na tentativa de identificar práticas relacionadas ao com-

\footnotetext{
^Endereço para correspondência: Escola Bahiana de Medicina e Saúde Pública. Av. Dom João VI, 275 - Brotas, Salvador, BA - Brasil. CEP: 40290-000 E-mails: kaikecoj@gmail.com, santana_hellen@hotmail.com, marildacastelar@gmail.com

Os dados completos dos autores encontram-se ao final do artigo

${ }^{1} \mathrm{O}$ artigo foi escrito em linguagem gendrada empregando o feminino e o masculino 'a/o' em todas as palavras possíveis, independente de construções socais e gramaticais, com o intuito de contribuir com a exclusão do sexismo de linguagem, conforme orienta a Nota Técnica 01/2009 intitulada Reflexões sobre o sexismo na linguagem", publicada pelo Conselho Regional de Psicologia da Bahia.
}

bate do racismo institucional nos serviços públicos. Com isso, buscou-se propiciar um panorama atual das dificuldades encontradas por esse profissional e detectar suas estratégias de enfrentamento para as demandas mencionadas em seus relatos.

De acordo com Souza (2006), embora as mais congruentes discussões e propostas com aspecto assistencial estivessem presentes no âmbito social brasileiro, em meados da década de 1950 a busca pela valorização efetiva do homem como cidadão de direitos só ganha mais ímpeto com a Constituição de 1988, em que os princípios da igualdade, cidadania e democracia passam a ter maior relevância no âmbito social. Surge, então, a emergência por novos arranjos facilitadores de trabalho, tornando-se uma necessidade básica o desenvolvimento e aperfeiçoamento de estratégias que fortaleçam a legitimação dos indivíduos como sujeitos de direitos.

Sabe-se que as/os profissionais de psicologia possuem um enorme potencial como agentes de transformação social, e, dessa maneira, conhecer as suas práticas profissionais, em especial as suas respectivas demandas profissionais, pode gerar novas fontes de avanço nessa área. Esta pesquisa possui relevância no que se refere ao combate do racismo institucional como uma demanda social emergente, uma vez que essa modalidade de racismo parece estar velada; entretanto pode produzir um elevado grau de sofrimento psíquico ao indivíduo que vivencia tal sofrimento.

Nesse sentido, diversas questões são colocadas em discussão no tocante às relações raciais, para o desenvolvimento de estratégias que podem auxiliar no rompimen- 
to dos paradigmas socialmente construídos. No entanto, esta análise faz menção essencialmente à presença das/os profissionais de psicologia nos serviços públicos, considerando os princípios do código de ética da categoria e o seu compromisso ético com o social.

Partindo da premissa de que as práticas psicológicas estão permeadas de desafios a serem enfrentados, espera-se, com esta pesquisa, explicitar a atuação dos profissionais de psicologia na esfera dos serviços públicos de algumas unidades de saúde de Salvador-Bahia, bem como identificar aspectos relevantes relacionados ao racismo institucional em sua realidade concreta. A pesquisa pretendeu estimular a produção de conhecimento que auxilie as práticas psicológicas no atendimento às necessidades oriundas do meio social, considerando a existência de grandes desafios reconhecidos pelas/os psicólogas/os diante da diversidade social.

\section{Políticas públicas e a busca pela legitimação dos Direitos Humanos}

A elaboração de uma conceituação sobre as políticas públicas é complexa e bastante diversificada entre os mais variados autores no âmbito científico. Portanto, conhecer o surgimento desse campo torna-se importante para compreender os mecanismos de produção e desdobramentos que ele se propõe a oferecer. De acordo com Souza (2006), no âmbito do Estado propriamente dito, a introdução da política pública nasce na Europa como área do conhecimento, sendo uma subárea da ciência política. Já nos EUA, ao contrário, as políticas públicas aparecem nos moldes acadêmicos como forma de análise das ações governamentais, no papel do Estado e as suas vicissitudes, sendo essa temática fruto do contexto sociocultural oriundo da Guerra Fria.

A busca por uma definição precisa sobre o significado das políticas públicas permeou diversos debates ao longo das últimas décadas. Durante toda essa trajetória, a área contou com quatro grandes pioneiros fundadores, que partilhavam, porém com abordagens diferentes, do mesmo tema. São eles: Charles Lindblom, David Easton, Harold Dwight Lasswell e Herbert Simon (SOUZA, 2002).

No entanto, para suscitar alguns elementos comuns na especificação conceitual, pode-se afirmar: as políticas públicas surgem para responder a demandas da população. São diretrizes para a elaboração de ações e propostas que podem viabilizar uma atividade concreta para o atendimento de uma necessidade coletiva de um determinado segmento ou território.

As políticas públicas desenvolvem-se na Europa em meio aos conflitos e contradições depois da década de 1950 , o que pode ser observado nas divergentes estruturas e mudanças no cenário político. Diante desse contexto, destina-se ao Estado, no fim do século XIX, a função interventiva de proteção e promoção social, na qual ele passou a ser o organizador político e econômico da sociedade - é o modo de organização denominado Estado de Bem-Estar Social (GONÇALVES, 2010).

Fractal, Rev. Psicol., v. 32 - n. 2, p. 142-153, 2020
Assim, a consideração de um conceito delimitado sobre as políticas públicas põe em evidência o olhar minucioso para a sua própria natureza, ou seja, os embates, relações de poder, ideias e preferências a serem priorizadas. É justamente a busca por interesses, atrelada aos recursos materializados pelas disputas pelo poder entre os grupos sociais, que se configura como o cerne para a formulação das políticas públicas. Essa luta é mediada por instituições políticas e econômicas que levam as formulações das políticas públicas para certa direção e privilegiam alguns grupos em detrimento de outros dentro do sistema democrático. De fato, o que se pode conjecturar é que "não existe uma única, nem melhor definição sobre o que sejam as políticas públicas" (SOUZA, 2006, p. 24); no entanto, podemos resumi-las como um campo do conhecimento, através do qual os governos traduzem seus propósitos em programas, ações e práticas profissionais, que produzirão resultados ou transformações esperadas no mundo real (SOUZA, 2002).

A busca pela integralidade de um cidadão de direitos é colocada em questão. Com a Constituição de 1988, as políticas de saúde ganham legitimação e, por conseguinte, passa-se a ter um olhar mais amplo para os princípios que permeiam o viver em sociedade, levando em consideração as especificidades do ser humano (SOUZA, 2006). Sintonizada com os princípios éticos, morais e culturais da sociedade, a psicologia, enquanto ciência e profissão, tem-se preocupado, ao longo do tempo, em oferecer contribuições de caráter multifatorial para as demandas sociais.

A consolidação da atuação da psicologia no interior das políticas públicas perpassa por duas vias: por um lado faz menção à institucionalização representativa da psicologia, realizada pelo sistema conselhos (CFP - Conselho Federal de Psicologia juntamente com os Conselhos Regionais) e todas as outras instâncias relacionadas a essa entidade, bem como suas representações em conselhos de direitos. Sob outra perspectiva, refere-se diretamente à própria atuação das psicólogas nos espaços públicos em que estão envolvidas e na construção cotidiana de determinada política.

Segundo Dimenstein (1998 apud LIMA, 2005), os consequentes fatores determinantes para incluir a entrada de profissionais de psicologia nos serviços públicos de saúde foram especificamente três: o aumento do número de psicólogas/os junto com a disseminação da área de Recursos Humanos e o contexto das políticas de saúde no fim do século XX; a pouca procura por consultórios psicológicos pela população na década de 1980; e, por fim, destaca-se a movimentação da categoria em busca de uma redefinição de seu papel social.

Segundo Gonçalves (2010), fazem parte da história da psicologia teorias que visavam aos anseios da elite, com o objetivo de diagnosticar e categorizar os indivíduos. Essas marcas construídas historicamente acabaram por enquadrar os sujeitos em padrões socialmente construídos e, consequentemente, passaram a invisibilizar os próprios direitos que lhes são devidos. 
Diante desse cenário, é importante considerar o aspecto das relações que se atrelam diretamente à subjetividade, considerando que a potencialização da dimensão subjetiva é uma premissa fundamental para garantia dos direitos humanos. Essa premissa corrobora com Bock (2009), que menciona a psicologia sócio-histórica no processo de constituição do sujeito como um indivíduo ativo, que se constrói nas relações que estabelece.

Atualmente, a psicologia começa a adotar uma postura oposta aos seus primórdios, produzindo conhecimentos que podem romper com a visão "higienista" e "normalizadora" de indivíduo e, dessa maneira, atuando de forma a garantir a autonomia dos sujeitos. Isso reitera as considerações de Gonçalves (2010), ao afirmar que as práticas psicológicas têm se empenhado na valorização do sujeito, o que possibilita a diminuição dos efeitos das desigualdades no âmbito macrossocial.

Nas duas últimas décadas, o Conselho Federal de Psicologia (CFP) realizou inúmeros eventos, pesquisas e publicações que servem como referências para a atuação da categoria, a exemplo do documento "Referências Técnicas para a Prática de Psicólogas/os no Centro de Referência Especializado da Assistência Social" (CREAS), possibilitando subsidiar as práticas psicológicas frente às políticas públicas. Esse documento apresenta-se como um exemplo de marco regulatório importante, tanto para nortear as práticas terapêuticas nesses espaços quanto para "[...] estabelecer novas interlocuções com as esferas de formulação, gestão e execução das políticas públicas" (CFP/CREPOP, 2009, p. 19). Iniciativas como essa contribuem para a mudança do papel da psicologia nas políticas públicas.

Desse modo, um cenário complexo de desafios poderia se ancorar nas práticas dos/as profissionais de psicologia, tornando-se essencial que questões complexas, como, por exemplo, a temática das relações raciais, sejam observadas sob um viés crítico e contextualizadas pelos profissionais de saúde. Afinal, tais questões manifestam-se no âmbito social em forma de gestos, discursos e atitudes, sendo, muitas vezes, ancoradas em um minucioso processo sócio-histórico de invisibilidade que afetam diretamente as relações de poder e produzem sofrimento psíquico, em especial no âmbito das instituições públicas de saúde.

\section{Relações raciais e o racismo institucional}

As relações raciais no Brasil trazem consigo uma série de embates que podem ser analisados a partir de um construto sócio-histórico atrelado aos pressupostos ideológicos de uma elite branca e interracializada em torno da problemática envolvendo o "mito da democracia racial". Este mito contém, em suas premissas, a disseminação no imaginário social de que "somos todos iguais perante a lei". O mito “[...] alimenta um discurso que propaga a existência de uma relação harmoniosa e igualitária entre brancos e negros, o que não corresponde às situações concretas que a população negra vivencia" (FERREIRA; CAMARGO, 2011, p. 377). Com a assinatura da Lei Áurea, em 1888, e um ano após a Proclamação da Repúbli- ca, pressupõe-se que tanto brancos como negros tiveram acesso de forma igualitária a direitos semelhantes, em termos de saúde, moradia, oportunidades de trabalho e de educação, entre outros. Assim, esse discurso passou a se impregnar no imaginário social e mascarou desigualdades existentes na relação entre brancos e negros.

Segundo destaca Domingues (2005, p. 118) “O mito da democracia racial era uma distorção do padrão das relações raciais no Brasil" e, desde a Colônia, perpassando pelo período do Império, os negros foram vistos como subordinados e inferiores à classe dominante nas relações de poder, que sempre foi ocupada por brancos. A institucionalização se desenvolve como parte estruturante da sociedade, nas organizações estatais, em vários níveis, tais como econômico, político e cultural. O mito da democracia racial torna o racismo um modo operante camuflado nessas instituições que produzem desigualdades raciais.

Por outro lado, é preciso reconhecer que, com o passar dos anos e de forma implícita, novas maneiras de sustentação desse pensamento vão ganhando outras roupagens, sendo elaboradas, portanto, as práticas oriundas da institucionalização, representando um fator crucial nas manifestações veladas de racismo. A nomenclatura denominada racismo institucional (RI) - também conhecido como racismo sistêmico, teve origem nos Estados Unidos, no fim da década de 1960. Ao fazer referência aos membros do grupo Panteras Negras, Charles Hamilton e Stokely Carmichael expressam conceito similar conforme citado abaixo.

O fracasso das instituições e organizações em prover um serviço profissional e adequado às pessoas devido à sua cor, cultura, origem racial ou étnica. Ele se manifesta em normas, práticas e comportamentos discriminatórios adotados no cotidiano do trabalho, os quais são resultantes da ignorância, da falta de atenção, do preconceito ou de estereótipos racistas. Em qualquer caso, o racismo institucional sempre coloca pessoas de grupos raciais ou étnicos discriminados em situação de desvantagem no acesso a benefícios gerados pelo Estado e por demais instituições e organizações (BRASIL, PNUD, 2005, p. 6).

Assim, pode-se mencionar que o racismo institucional é uma modalidade de racismo - o do modo organizacional - e faz referência a um mecanismo estrutural que suscita a exclusão seletiva de alguns grupos subordinados - ciganos, indígenas e negros em detrimento de assistências e benefícios disponibilizados (LÓPEZ, 2012). Algumas características implícitas fazem referência à prática do racismo institucional, tais como: a diferença do tempo de consulta entre mulheres brancas e negras; dependendo da orientação religiosa do profissional de saúde, eles evitam realizar visitas domiciliares para não entrarem em terreiros de religiões de matriz africana, não atendendo aquela população; também é comum em certos ambientes de trabalho chefias orientarem seus funcionários negros e negras a prenderem o cabelo quando a função realizada não exige cabelo preso, enquanto outros profissionais brancos não recebem a mesma orientação, dentre outras (SANTOS, 2012). 
Constata-se que o racismo institucional não se apresenta simplesmente nas atitudes individuais das pessoas, mas, antes disso, está impregnado na lógica estrutural da organização. Segundo López (2012), a luta pelo enfrentamento explícito do racismo institucional ganha mais força a partir do início do século XX com a Conferência Mundial contra o Racismo, cujo objetivo foi a efetivação do compromisso social referente à promoção da igualdade racial. Partindo desse pressuposto, parece essencial mencionar o que acontece no cotidiano das organizações como estratégia de sensibilização dos servidores públicos contra essa modalidade de racismo, o que possibilita construir novas maneiras de enfrentamento para a prática profissional.

Contudo, se é inexistente a reflexão nos âmbitos institucionais, a implicação disso é a reprodução ilegítima dos mecanismos racistas na sociedade, ajudando, assim, a alavancar os impactos na saúde dessa população. Conforme mostra o Instituto de Pesquisa Econômica Aplicada (IPEA), no ano de 2008, de acordo com os dados de raça/cor, o número de atendimentos de pessoas negras no SUS foi de quase $70 \%$, revelando a forte dependência dessa população da assistência prestada pelo governo (IPEA, 2011).

É importante salientar que essa modalidade de racismo pode trazer consigo consequências drásticas à vida de um indivíduo, uma vez que ele, não tendo acesso ao seu direito, pode entrar em um estado de sofrimento psíquico. Uma vez que os princípios que norteiam a prática do racismo institucional são ancorados na "política do silêncio", apresentam-se de forma velada, sendo, assim, de difícil detecção por parte dos usuários e até mesmo dos profissionais, que dificilmente param para analisar as implicações de suas ações e regras. De acordo com López (2012), a questão do anonimato, aqui prefigurado, está relacionada ao processo da institucionalização. Afinal, esta não pode ser atribuída a um único indivíduo isoladamente, mas se faz presente nas relações estabelecidas pelo sujeito.

Esse aspecto dialoga com Mattos (1994), que enfatiza a lógica impregnada nas instituições como aquela que parece se reportar a um cenário de alienação, e é justamente por essa estratégia "velada" que as elites tendem a se alimentar. Essa abordagem produz um sujeito dominado, que não consegue desarraigar-se do funcionamento escravocrata do sistema institucional. Os efeitos deste regime burocrático são percebidos nos mais variados aspectos de vida do sujeito, ultrapassando os muros do trabalho, ficando mais evidente nas instituições públicas.

Ainda segundo o mesmo autor, a alienação configura-se como aquilo que se manifesta como condição de opressão e de privação, sendo uma estrutura sólida, material e institucional da economia, geralmente relacionada ao poder ideológico que ratifica a manipulação contra o cidadão (MATTOS, 1994). Nessa perspectiva, o sujeito encontra-se afetado tanto pela violência simbólica a ele atribuída quanto pela exclusão do seu direito ao exercício da cidadania. $\mathrm{O}$ avanço do capitalismo legitima o paradigma da classe elitizada e, por consequência, exclui a garantia subjetiva da assistência às demais classes sociais.
Na saúde, essa especificidade ganha destaque ao se considerarem os resultados emitidos pelo Instituto de Pesquisa Econômica Aplicada (IPEA) referentes à característica da população mais atingida pelo processo de exclusão dos direitos - a população de classe baixa e negra. Segundo a pesquisa, cerca de $70 \%$ dessa população utiliza o Serviço Público de Saúde, o chamado SUS - dependentes (IPEA, 2011).

Na perspectiva de Mattos (1994), em relação às práticas de desigualdades e discriminação oriundas da própria instituição, percebe-se a existência invisível de um sistema de "retroalimentação", que, ao mesmo tempo em que aliena o serviço público, reforça e passa a gerar essa mesma alienação. Dessa forma, romper com esse sistema de alienação social tem sido a maneira encontrada por alguns gestores mais conscientes, a partir da atuação dos movimentos sociais. Com isso, a autonomia do sujeito torna-se a característica mais afetada com essa defasagem social.

O Programa de combate ao racismo institucional (PCRI), por exemplo, busca investir no combate ao racismo no âmbito do SUS, através de mudanças de comportamento, atitudes e práticas institucionais racistas, fomentando, portanto, a equidade em saúde (BAHIA, online). Como exemplo de desigualdades na saúde, destaca-se a dissertação "Médicos e pacientes têm sexo e cor? A perspectiva de médicos sobre a relação médico-paciente na prática ambulatorial" (SANTOS, 2012). Esse estudo evidenciou que médicos não dispensam a mesma qualidade de atendimentos às mulheres brancas e negras. Desse modo, fazem-se necessárias políticas públicas para minimizar as desigualdades de serviços, benefícios e oportunidades existentes. Vale, portanto, ressaltar que a diferença na cor da pele gera desigualdade em todas as esferas da vivência cotidiana dos negros.

Ainda convivemos constantemente com casos de clientelismo, uma vez que as políticas sociais no Brasil priorizam interesses econômicos e políticos, com o foco nos interesses privados (LIMA; SILVA; PEREIRA, 2015), o que acaba, por exemplo, ocasionando sucateamento no SUS e repercutindo no atendimento prestado à população. Os negros, portanto, têm seus direitos violados.

Portanto, saber se as/os psicólogas/os reconhecem a discriminação racial como uma fonte de sofrimento pode ser estratégico para o enfrentamento do racismo institucional. Assim, torna-se necessário conhecer os discursos de psicólogas/os, para se aproximar das concepções e práticas relacionadas à atuação frente ao racismo institucional, considerando tanto as repercussões do racismo como a maneira com que demandas provenientes dele são trabalhadas na prática profissional, promovendo, desse modo, reflexões sobre o racismo na formação e atuação em psicologia.

Em seus trabalhos, Silva (2009) tem mencionado a importância histórica do movimento negro como um dos grandes responsáveis pela descentralização da estrutura elitista, enfatizando, em seus discursos, a denúncia contra o racismo institucional na sociedade. De acordo com o Guia de enfrentamento ao racismo institucional 
(GELEDÉS, 2013), elaborado com a participação de instituições públicas, agências do Sistema ONU no Brasil e diferentes organizações da sociedade civil, o enfrentamento do racismo institucional está relacionado a dois eixos estruturantes: a cultura institucional, que busca a reafirmação do seu compromisso social para o enfrentamento interno nas organizações, e as manifestações para o público, que avalia as políticas, os serviços e as competências culturais (GELEDÉS, 2013).

De modo geral, o racismo institucional desestrutura a própria estabilidade do Estado, que se propõe a fornecer assistência de igual modo para todos, levando em consideração todas as especificações da vida dos sujeitos. É importante considerar que, no Brasil, o racismo institucional apresenta-se sob duas dimensões específicas e inter-relacionadas: a dimensão das relações sociais, com foco nas relações que se estabelecem alicerçadas em atitudes de discriminação e envolvem gestores, trabalhadores e usuários, e a política programática, dimensão esta que pode ser caracterizada pela produção e disseminação de informações relacionadas às experiências de produção de desigualdades sociais, "à capacidade em reconhecer o racismo como um dos determinantes das desigualdades; pelo investimento em ações e programas específicos para a identificação de práticas discriminatórias" (BRASIL, PNUD, 2005).

Não obstante, de acordo com os estudos de Schucman (2012), percebe-se um cenário que necessita desenvolver não apenas novos e constantes estudos relacionados aos brancos, mas que também, de maneira explícita, necessita elaborar outras formas de enfrentamento ao racismo, partindo da premissa de que os brancos legitimam, de maneira intencional ou não, as desigualdades raciais. Assim, a branquitude surge como um conceito científico de crescentes estudos no século XXI, fazendo menção justamente àqueles indivíduos brancos que tendem a reafirmar uma condição de privilégio no meio social. $\mathrm{O}$ racismo institucional opera de forma a induzir, manter e condicionar a organização e a ação do Estado, suas instituições e políticas públicas - atuando também nas instituições privadas, produzindo e reproduzindo a hierarquia racial (GELEDÉS, 2013).

Algumas/ns autoras/es contemporâneas/os têm sido fundamentais aos estudos sobre relações étnico-raciais no país, como Sueli Carneiro, Isildinha Nogueira e Kabengele Munanga. Este último, em entrevista concedida à revista Estudos Avançados, publicada sob o título "A difícil tarefa de definir quem é negro no Brasil" (MUNANGA, 2004), menciona que se aproximou do tema das cotas em 1995, através de comissão criada pela reitoria da USP, ocasião em que se deparou com desanimador levantamento do Instituto de Pesquisa Econômica Aplicada (IPEA), o qual evidenciou defasagem na escolaridade dos negros nas universidades brasileiras. Além de apontar as dificuldades de acesso e manutenção dos/as negros/as no ensino superior, o mesmo autor denuncia a ausência do/a negro/a em escolas de qualidade, pontuando que "a escola pública já apresentou melhor qualidade, mas o negro e o pobre não entravam nela" (MUNANGA, 2004, p. 53).
É importante refletir como as/os negras/os são violentadas/os no que diz respeito à possibilidade de conseguir investir no intelecto, o que consequentemente interfere nas oportunidades de trabalho e emprego. Muitas vezes, quando conseguem alcançar um processo formativo/educativo de qualidade, se deparam com olhares julgadores e precisam, portanto, provar que estão em uma empresa por conta da sua qualificação e que dão conta do trabalho. Essa desigualdade e desvalorização das/os negras/os nas empresas representa uma prática de racismo institucional.

Ainda no que diz respeito ao lugar que o corpo negro ocupa socialmente, a psicóloga Isildinha Nogueira (1999) afirma que a aparência funciona como garantia da integridade/qualidade de uma pessoa. De acordo com a aparência física, alguém pode ser considerado capaz ou não de cometer uma transgressão (atributos morais), por exemplo. Ou, ainda, ser capaz ou não de ocupar um determinado cargo.

Já a autora Sueli Carneiro (2003) discute questões relativas ao feminismo negro. Nesse sentido, dialoga com Suárez e Bandeira (2002), observando que as DEAMs (Delegacias Especializadas de Atendimento às Mulheres) apresentam dificuldades e imperfeições no seu modo de funcionamento. Porém, existe articulação para que as mulheres recebam tratamento equitativo, evitando condutas violentas. Contudo, outras delegacias não se alinham nesse mesmo propósito.

Observa-se que nos espaços em que as mulheres violentadas deveriam ser cuidadas, como delegacias, elas são recebidas com preconceitos e racismo, o que representa uma dupla violência. Toda mulher sofre com a violência de gênero, porém as negras apresentam maiores dificuldades em sair do ciclo de violência, devido às questões financeiras. Nesse sentido, conclui-se que diversas instituições afastam o corpo negro, como: escola, universidade, hospitais e delegacias.

De acordo com Lima (2005), torna-se necessária a observação discursiva dos profissionais diante das fragilidades que emergem em seus ambientes de trabalho, sendo esse aspecto essencial para a busca por soluções mais assertivas perante as demandas da população atendida, que, no caso de Salvador, é negra - e a maioria das psicólogas brasileiras, $67 \%$, se autodefine como brancas (LHULLIER, 2013).

Em suma, o racismo institucional expõe implicitamente vantagens que privilegiam determinados segmentos sociais em detrimento de outros, ocasionando, assim, uma inclusão perversa de classes historicamente desfavorecidas nos ambientes públicos. Faz-se necessário o questionamento da temática para a atuação de psicólogas inseridas nos mais diversos contextos, uma vez que o racismo institucional apresenta muitos desdobramentos e pode se manifestar em diferentes situações cotidianas; segundo López (2012), ele está presente em todos os espaços, inclusive em institucionais e organizacionais. 
Objetivamos, portanto, nos aproximar da percepção de como tem sido o enfrentamento do racismo institucional na atuação em psicologia em algumas unidades de saúde do município de Salvador, na busca de práticas que visam ao enfrentamento do racismo.

\section{Método}

A pesquisa é de caráter qualitativo; enquadra-se no campo da história oral temática, visto como método e técnica para coletar dados, a partir da vivência das pessoas relacionadas a temas preestabelecidos, de acordo com o projeto de pesquisa (MEIHY; RIBEIRO, 2011).

A fonte oral temática constitui-se como um mecanismo científico, que, em sua base primária, proporciona a obtenção de conhecimento. É exatamente por causa desse intuito que os conteúdos narrados passaram a ter relevância científica, uma vez que, ao se definir critérios e arranjos metodológicos, munidos de argumentos continuados e sistematizados, os diálogos passaram a ser legitimados profissionalmente através da própria necessidade de se aprofundar nas palavras, códigos e linguagens (RIBEIRO; MACHADO, 2014).

Ainda segundo as autoras, no campo da saúde o significado atribuído ao uso do método da história oral em pesquisas qualitativas justifica-se na medida em que traz a própria história e perspectivas do sujeito para dentro de uma realidade em investigação. Nesse sentido, as vozes desconhecidas e muitas vezes invisibilizadas pela cultura do silêncio passam de objetos de estudo a paralelamente construtoras de uma nova realidade social.

$\mathrm{O}$ estudo ocorreu prioritariamente em três etapas. A princípio, foram levantadas referências norteadoras do tema pesquisado, para a elaboração do roteiro de entrevista e revisão de literatura. Nesta etapa, foi analisada uma quantidade expressiva de artigos qualitativos que versavam sobre a realidade contextual da pesquisa sob o prisma de diferentes enfoques étnicos/raciais. Na escolha dos artigos, o tema "racismo" se configurou como a temática principal, no entanto, foi demarcado um recorte específico para as questões que direcionaram o estudo para a linha do racismo institucional. Com base nesse filtro, foi elaborado um roteiro semiestruturado com perguntas que visavam identificar a prevalência/existência do racismo institucional nos ambientes de trabalho dos profissionais, como por exemplo: O que é o racismo institucional? Você consegue identificar a existência do racismo institucional em seu ambiente de trabalho? Quais as medidas utilizadas para combater o racismo institucional? Existem práticas inovadoras no combate ao racismo institucional?

A segunda etapa consistiu no mapeamento dos profissionais de psicologia em unidades de saúde de Salvador por meio de ligações telefônicas. Essa etapa se iniciou com a identificação dos equipamentos de saúde que possuíam em sua equipe de trabalho profissionais de psicologia. Após esse processo foi realizado um levantamento telefônico com o objetivo de estabelecer uma aproximação com os diversos profissionais. Após esse rastrea-

Fractal, Rev. Psicol., v. 32 - n. 2, p. 142-153, 2020 mento, foi solicitada aos órgãos públicos a liberação dos mesmos para a realização das entrevistas e coleta de dados nos seus respectivos locais de trabalho.

$\mathrm{Na}$ terceira etapa, foram realizadas sete entrevistas, tendo como participantes cinco mulheres e dois homens, o que evidencia o lugar das mulheres como representantes principais da categoria profissional (LHULLIER, 2013). Todas atuavam em algum tipo de dispositivo de saúde, em quatro unidades de saúde de Salvador - um Centro de Atendimento Psicossocial (CAPS), dois hospitais e uma Unidade Básica de Saúde (UBS) -, tendo como base um roteiro semiestruturado contendo dez questões. As perguntas, inicialmente, foram de ordem sociodemográfica e, posteriormente, abrangeram questões específicas diretamente relacionadas ao tema da pesquisa, a saber, as relações raciais, racismo institucional e a atuação dos profissionais de psicologia. Todas as entrevistas foram gravadas e realizadas no próprio setor de trabalho dos profissionais, com salas adequadas e horários previamente agendados. Cabe salientar que nenhum/a psicólogo/a criou resistência para assinar o TCLE, o qual autoriza a gravação da entrevista em áudio.

Do ponto de vista dos cuidados éticos, o estudo é o recorte de uma pesquisa mais ampla aprovada pelo Comitê de Ética CAAE 33098814.0.0000.5544. Destacamos que os entrevistados tiveram seus nomes preservados, sendo identificados neste estudo apenas por uma letra, seguida de um número, tendo em vista assegurar o sigilo profissional de cada um (P1, P2 etc.). E, por serem a maioria, as mulheres doravante serão tratadas com flexão de gênero feminino, para corroborar também com o sigilo.

A coleta dos dados seguiu os procedimentos da história oral, a qual exige um projeto de partida bem definido quanto ao objetivo da pesquisa e à escolha das pessoas que serão entrevistas. Nesse sentido, os encontros foram planejados; gravados em áudio, com perguntas, estímulos, de modo a explorar a lógica e construção dos discursos e respostas (MEIHY; RIBEIRO, 2011). Todas as entrevistas foram transcritas e conferidas posteriormente, para a análise do conteúdo, de acordo com Bardin (2009), que objetiva aproximar-se do que aparece nos discursos dos entrevistados. Para suporte teórico da análise, foi utilizado um referencial teórico basicamente sobre políticas públicas e racismo institucional, mencionado no início do presente artigo.

\section{Resultados e discussão}

$\mathrm{Na}$ busca por analisar as percepções das psicólogas/ os sobre racismo institucional em suas práticas profissionais, este artigo chegou a duas sessões de análise: a primeira denominada "Invisibilidade do racismo institucional e seus desdobramentos nas práticas profissionais", que contemplou os relatos que demonstram a ausência da discussão sobre relações raciais na formação e a falta de atualizações/capacitações. A segunda, denominada "Concepções sobre racismo institucional das/os profissionais", registra a análise dos entendimentos das/os psicólogas/os diante do racismo institucional.

Invisibilidade do racismo institucional e seus 


\section{desdobramentos nas práticas profissionais}

Ao serem indagadas/os sobre a existência do racismo institucional em seu local de trabalho, as/os psicólogas/ os afirmaram não observar essa prática nos ambientes em que atuam. As/os profissionais demonstram possuir apenas uma vaga noção sobre o conceito de racismo institucional. Assim, foram selecionados relatos que retratam a invisibilidade do racismo institucional na graduação e na prática em psicologia, bem como a escassez de intervenções/capacitações sobre o programa de racismo institucional para o enfrentamento do racismo.

Não obstante, a reflexão sobre a invisibilidade do racismo institucional nos serviços públicos configura-se como um dos aspectos mais importantes a serem explicitados. Os relatos demonstraram a ausência da discussão sobre racismo institucional na formação, bem como a falta de atualizações/capacitações para uma atuação mais qualificada frente às demandas da população negra.

As/Os profissionais reconhecem o quanto é importante atualizar-se constantemente e que, muitas vezes, faltam capacitações para mantê-las/os qualificadas/os. Por exemplo, verifica-se a falta de incentivo para participação em espaços que podem manter as/os profissionais atualizadas/os em temas emergentes da profissão, o que pode possibilitar trocas de conhecimento, experiências e constante atualização.

Por outro lado, esses espaços podem, também, não estar sendo qualificados como possibilidades de formação, como palestras, seminários e congressos. Algumas psicólogas da Saúde Pública de Salvador evidenciaram, em suas falas, que o Programa de combate ao racismo institucional no SUS não está sendo disseminado em seu local de trabalho, apesar de ser ele um potente instrumento para uma formação consistente e um aperfeiçoamento profissional para intervenção sobre o tema. Observa-se que alguns profissionais acreditam que um aspecto a melhorar na sua prática é a oportunidade de incentivo a atualizações.

[...] pensar em maneiras de incentivo em termos de participação, de atualização, de aproximações do que a academia produz, as pesquisas que são feitas e as práticas cotidianas, eu acho que se precisaria pensar [...] também em termos de incentivo às reflexões [...] enfim, entre nós lá eu acho que o incentivo a você ter ações inovadoras, a pessoas que venham trazer as novidades, fazer atualizações. Isso é sempre bem-vindo ( $\mathrm{P} 1,52$ anos).

Ficou nítida a ausência de atualizações/capacitações nos espaços em que as psicólogas atuam na atualidade. No quesito cor, por exemplo, três profissionais se autodeclararam como pardas, três como brancos e um não soube responder - este dado evidencia que ainda existem profissionais sem afinidade com o tema, não possuindo, dessa forma, consciência sobre a sua própria cor.

Faz-se necessário que a categoria não continue reproduzindo, na prática, somente uma psicologia tradicional, conforme a psicóloga acima menciona, e parece existir uma abertura para novos aprendizados e mudanças. Acredita-se que questionamentos, reflexões e capacitações sobre o tema vêm a ser o início desse processo, uma vez que ele se revitaliza ao fazer a temática circular entre estudantes e profissionais, o que já é considerado um passo importante, tanto nas salas de aula, em que o ensino das relações étnico-raciais pode ser discutido, como nos mais diversos espaços de atuação para enfrentamento do racismo.

Os profissionais parecem desconhecer intervenções voltadas para o racismo institucional no seu ambiente de trabalho, o que evidencia que não recebem capacitações desse programa específico para atender à demanda racial, considerando que a cidade de Salvador possui ampla maioria de negros compondo sua população usuária dos serviços públicos de saúde.

Outra questão que não pode ser desconsiderada é o fato de as profissionais possuírem uma idade média de 42, 43 anos de idade. Esta afirmativa é crucial para o entendimento do processo histórico de formação acadêmica desses profissionais, que, mesmo não sendo o foco principal de análise da presente pesquisa, possui relevância na compreensão das várias mudanças no perfil de ensino de psicologia no Brasil e, respectivamente, daquelas que vêm ocorrendo em suas diretrizes curriculares nos últimos dez anos, a exemplo da implementação de disciplinas que discutem relações raciais no ensino, baseada na Lei 10.639, de 2003.

A formação acadêmica vem a ser, portanto, um fator essencial para a atuação das profissionais de psicologia frente ao racismo institucional, acoplando, inclusive, disciplinas específicas sobre as relações raciais. Observou-se que a atuação e a formação em psicologia não fomentam, de forma consistente, o debate sobre relações raciais, e a atuação fica limitada, não contemplando o enfrentamento do racismo institucional.

Esse dado torna-se relevante diante da observação de Gonçalves (2010), que menciona a crescente investigação da psicologia por questões que são produzidas pelas desigualdades sociais, como, por exemplo, a humilhação, a opressão e a discriminação sociais. Observa-se, portanto, o empenho na valorização do sujeito, o que possibilita a diminuição dos efeitos das desigualdades.

Esse posicionamento reforça os resultados encontrados nos estudos de Lima (2005), que salienta como um dos pontos essenciais para a inserção de profissionais de psicologia nos serviços públicos de saúde o reconhecimento da necessidade do seu contínuo aperfeiçoamento profissional, tal como foi observado no discurso das/ os psicólogas/os. Tais especificidades são apresentadas como condições essenciais para a conscientização por parte das/os profissionais da importância de uma atuação crítica em psicologia, proporcionando um olhar adequado para as peculiaridades da atuação profissional nos mais diversos contextos em que venham a atuar.

\section{Concepções sobre racismo institucional dos profissionais}

Essa categoria contemplou o entendimento das/os psicólogas/os diante do racismo institucional e da existência de práticas racistas nos espaços em que atuam, bem como buscou-se analisar as intervenções utilizadas pelos participantes no enfrentamento do racismo. 
Observa-se, a seguir, a compreensão do racismo institucional na concepção de uma das profissionais entrevistadas. A psicóloga demonstrou não problematizar a posição hierárquica nos cargos da instituição em que atua. Porém, a sua fala demonstra, explicitamente, a existência de desigualdade racial.

Não... não observo isso, no [...] [hospital] eu convivo com muitos técnicos de enfermagem que são negros, são pessoas, muitas vezes... de um nível socioeconômico próximo. E, em alguns aspectos de usuários, eu não observo, pode ser que me escape mesmo. Mas eu não observo o racismo não, nos discursos dos colegas, dos médicos, de quem atendo, não. Tem muitos funcionários negros no hospital, não tem, enfim $[\ldots]$ ( $\mathrm{P} 1,52$ anos).

No relato acima, a psicóloga não reconhece na instituição à qual pertence a prática de racismo, o que justifica pela presença de negros como técnicos e com nível socioeconômico próximo ao seu. Observa-se que o negro acaba sendo incluído de maneira desigual no mercado de trabalho, por conta do seu fenótipo, independentemente das qualificações profissionais que apresente. Identificar onde estão os funcionários negros da instituição já deveria ser um reconhecimento da existência de racismo.

A desconstrução do racismo só vai ocorrer, de fato, se as instituições adotarem programas como de mobilidade hierárquica, de inclusão no trabalho, ou ainda os chamados programas de diversidade no trabalho. $\mathrm{O}$ que se vê, na maioria das instituições privadas ou públicas, é o racismo institucional imperando com uma estratificação social de distribuição hierárquica pela cor de seus funcionários, negros em cargos subalternos e brancos no topo.

A psicóloga menciona, também, que não observa desigualdades raciais para com os usuários do hospital, o que contradiz os achados de Santos (2012), que discute as desigualdades vivenciadas pelos negros nos serviços de saúde.

Discurso de outra psicóloga sobre o racismo institucional “... tratar essas pessoas desigualmente dentro da instituição, eu acho que seria prática de racismo institucional" (P2, 35 anos). Nesse relato, a psicóloga parece identificar que algo poderia estar em desacordo com o programa de racismo institucional na instituição em que atua, o que corrobora os dados de pesquisas que já identificaram que mulheres negras são atendidas em serviços de saúde de maneira desigual em relação a mulheres brancas, constatado no estudo de Santos (2012).

Os relatos mostram, sob diferentes pontos de vista, discursos que culminam na invisibilidade do racismo institucional e demonstram que alguns profissionais revelam não enxergar as manifestações do racismo nas instituições em que atuam.

Racismo institucional... na minha prática eu não consigo ver o racismo, eu atendo pessoas aqui de todas as cores, todas as possibilidades financeiras também, porque a gente atende... claro que nosso grande público aqui são pessoas que têm uma situação social complicada. Até de alguns graves, mas também eu atendo pessoas de situação social econômica, boa também, então assim. Eu não consigo ver nada que separe... aqui eu não acho que a gente tenha essa dificuldade $[\ldots]$ ( $\mathrm{P} 3,32$ anos).

A entrevistada acima nega a existência do racismo na instituição em que atua, nega a existência dessa "dificuldade". Acredita que não existe nada que separe a população que atende, reconhece que a maioria atendida apresenta dificuldades sociais e econômicas.

Observa-se, no relato a seguir, que ainda existem profissionais que não possuem afinidade com o tema; inclusive sem consciência sobre a sua própria cor. "Não. Eu não consigo observar.. bom, mas eu também estou um pouco cega, não é? Eu não venho..., eu não poderia... Eu não sei qual é minha cor" (P6, 33 anos). A psicóloga, além de mencionar que não consegue observar o racismo na sua prática, acrescenta que não sabe qual é a sua própria cor. Reconhece também que pode estar um pouco cega em relação às manifestações de racismo.

Uma das entrevistadas, inclusive, confunde racismo e discriminação, o que evidencia, mais uma vez, o desconhecimento dos profissionais sobre relações raciais, como se vê a seguir.

Eu não verifiquei isso. Eu sei de relatos de usuários em relação aos espaços em que eles se sentiram discriminados, não aqui na instituição. Mas fora dela e a gente tem que trabalhar isso porque realmente o preconceito existe, é real, preconceito em relação... Ah... O que você fala é racismo em relação à raça, não é? Eu falo em relação a ter um paciente de transtorno mental ( $\mathrm{P} 4,53$ anos).

A profissional acima acredita que não existe a dificuldade em se deparar cotidianamente com o racismo na instituição em que atua. Porém, segundo López (2012), o racismo está presente nos espaços institucionais e organizacionais. Mesmo que seja sutil, velado, ainda assim ele está lá. Nesse relato, a entrevistada também não se dá conta do descaso secular do Estado para com a população negra no Brasil e da dívida histórica da escravidão que nunca foi reparada.

Esse fato constatado, por si só, constitui racismo institucional de um município que não providencia condições adequadas de atendimento com qualidade para sua população de ampla maioria negra, sucateando o SUS, mantendo o clientelismo. A psicóloga parece não reconhecer que aquilo que está fora da instituição também se manifesta dentro das instituições, diferentemente do que relatou.

De acordo com o Guia de enfrentamento do racismo institucional (GELEDÉS, 2013), o processo de invisibilidade acaba sendo refletido em maior escala na dimensão pragmática do racismo institucional, uma vez que é através das políticas e ações governamentais que são produzidas vulnerabilidades de grupos e indivíduos que sofrem cotidianamente com o racismo.

Por outro lado, esses mecanismos velados de desprezo a determinadas identidades sociais geram efeitos psicossociais, como, por exemplo, influência negativa em sua autoestima, autoconfiança, entre outros. De acordo com o manual, a estrutura de invisibilidade do racismo institucio- 
nal perpassa os mais variados momentos da organização, sendo um processo que dificulta a realização dos atendimentos compatíveis com as necessidades dos sujeitos.

As profissionais, ao admitirem a invisibilidade do racismo institucional, acabam por reafirmar os estudos de Silva (2009), que enfatiza a importância do movimento negro e feminista no combate a todas as formas de ocultamento dos direitos, em especial aqueles relacionados à saúde da população negra. Cabe salientar que, historicamente, a militância, enquanto mecanismo de transformação social, tem se empenhado na denúncia de todas as formas de afronta ao Estado democrático de direito, comprometendo-se com o enfrentamento de políticas organizacionais que produzem desigualdades, preconceito e discriminação das classes subalternas.

No que diz respeito à compreensão das/os psicólogas/os sobre racismo institucional, observa-se que alguns deles demonstram entender como o racismo opera nas instituições, fazendo sofrer quem convive com a desigualdade racial. Porém, as/os profissionais evidenciam não conhecer o conceito de racismo institucional. Observa-se que, mesmo com a proposta da Lei 10.639, de 2003, que traz entre suas atribuições a discussão das concepções étnico-raciais no ensino, ainda existem muitas instituições de ensino que não se adequaram à lei.

O relato a seguir apresenta justamente a reflexão diante de alguns questionamentos sobre como devemos atuar.

Eu acho que, antes de mais nada, tem que explicitar, não é? Se você presencia, é preciso que aquilo seja explicitado não sob a forma de confronto nem sob a forma, digamos, pedagógica, de você estar chamando, mas isso precisa ser dito, ser mostrado para sensibilizar aquele que tem uma conduta racista de modo tal que ele entenda e possa se fazer, ele próprio, também um agente ( $\mathrm{P} 1,52$ anos).

Embora as/os psicólogas/os tenham mencionado não presenciar práticas do racismo institucional em suas vivências profissionais, emerge, no discurso acima, a importância de explicitar práticas racistas, as quais se apresentam, muitas vezes, de maneira velada nos âmbitos institucionais, para sensibilizar e transformar atitudes opressoras em formas pelas quais as pessoas decidiram ser agentes contra o racismo.

Conforme referido anteriormente por López (2012), é essencial mencionar estratégias de sensibilização direcionada aos servidores públicos contra o racismo, o que possibilita construir novas maneiras de enfrentamento para a prática profissional. Contudo, se é inexistente a reflexão sobre relações raciais nos âmbitos institucionais, como se justifica o descaso com as condições da saúde pública de forma geral? É preciso contextualizar também, de forma mais ampla, o racismo institucional e manter a atenção no dia a dia sobre como a população negra está sendo atendida nos serviços públicos de saúde.

As unidades de saúde pesquisadas no município de Salvador demonstraram não estar disseminando programas específicos já existentes relacionados ao racismo institucional, confirmando, assim, a invisibilidade histórica do tema em análise.
No entanto, embora os entrevistados tenham mencionado o desconhecimento do tema, segundo López (2012), nasce em 2005, no Brasil, o Programa de combate ao racismo institucional por meio de uma parceria com várias entidades públicas, com o intuito de oferecer visibilidade de ações efetivas no enfrentamento do racismo institucional, especificamente no âmbito da saúde.

Porém, após uma década de existência do programa, ainda é presente nos relatos dos entrevistados a ausência de práticas e ações que enfoquem a discussão dessa temática no cotidiano de trabalho. Dessa forma, é perceptível uma fragilização nos serviços públicos, o que interfere na atuação profissional frente à especificidade das relações raciais.

Embora alguns participantes tenham relatado não enxergar o racismo na prática profissional, não significa que ele não ocorra nos espaços em que atuam. Por outro lado, eles afirmam a impossibilidade de se pensar, por exemplo, em uma política de humanização sem que haja menção desse embate sociopolítico sobre o racismo institucional. Dessa maneira, a importância do tema não se restringe apenas aos aspectos observáveis do estudo, mas envolve uma significativa reflexão sobre as próprias habilidades e competências necessárias às práticas profissionais, garantindo, dessa forma, consciência crítica advinda do tema em análise.

De acordo com o Guia de enfrentamento do racismo institucional (GELEDÉS, 2013), às dimensões que permeiam o enfrentamento desse tema ultrapassam as dimensões organizacionais, que precisam ser questionadas de maneira contextualizada, levando em consideração os aspectos históricos, sociais, políticos e econômicos.

Diante dos dados coletados, ficou evidente que os participantes não tinham informações a respeito de práticas inovadoras de outros profissionais, vinculadas ao racismo institucional. Esse aspecto pode ser observado na fala de alguns profissionais.

Não vejo nada muito voltado para isso, o que eu vejo, que eu não sei se se configura com o que eu lhe falei, essa questão da rede cegonha eu não sei se ela se encaixaria nessa coisa do racismo... se entraria no racismo institucional eu vejo muito isso dar... de tentar humanizar a assistência nessa área... o que eu vejo mais, apesar de não ser da minha área, que eu vejo discussões acontecendo, às vezes a reunião acontecendo da rede cegonha, voltada para essa questão da mulher, não é? E da humanização do parto (P2, 35 anos)

Não... Não vejo nada (P1, 52 anos)

Observa-se que as/os profissionais de psicologia não conhecem outras/os psicólogas/os que atuem perante o racismo. Observa-se a inexistência de técnicas que deem suporte procedimental aos profissionais, o que acaba deixando-os sem saber como atuar diante desse enfrentamento, o que também aponta o desconhecimento de aspectos relacionados às relações raciais. Em suma, as questões procedimentais da categoria profissional proporcionam um panorama de como estamos lidando com as especificidades raciais. As fragilidades que envolvem a vivência das/os psicólogas/os nos serviços públicos são de natu- 
reza fragmentada (ou multifacetada) e, por conseguinte, trazem impactos negativos na sua maneira de qualificar e atender às demandas oriundas dos serviços de saúde.

No que diz respeito à atuação das/os psicólogas/os, observa-se a existência de práticas tradicionais, como atendimentos individuais, e poucos mencionam práticas grupais, oficinas e visitas domiciliares, o que ratifica a constatação de que o racismo institucional é operado coletivamente por equipes, normas locais escritas, verbais e não verbais, facilmente detectado nos resultados do descaso da saúde pública, em cidades com alto índice de população negra, como é o caso de Salvador.

Nesse sentido, fazem-se necessárias estratégias que considerem o racismo institucional em sua atuação para enfrentamento do racismo; contudo não foram observadas práticas mais consolidadas na atuação dos profissionais entrevistados.

\section{Considerações finais}

$\mathrm{O}$ aprofundamento da presente pesquisa torna-se essencial para a contribuição e o aprimoramento da atuação profissional perante o racismo institucional nas unidades de saúde do município de Salvador, sendo que, através da percepção das suas próprias práticas de trabalho, os profissionais de saúde podem atuar de modo mais qualificado na saúde pública. No que se refere às/aos psicólogas/ os, é evidente que o saber psicológico apresenta um grande potencial para o enfrentamento das demandas sociais e raciais; no entanto, torna-se cada vez mais necessário o contínuo aperfeiçoamento profissional da categoria, com ênfase na construção da consciência racial.

No que diz respeito às relações raciais, o combate ao racismo institucional evidencia uma problemática de ordem social e, dessa maneira, torna-se fundamental que, desde a formação acadêmica, a temática racial possa ser trabalhada de maneira crítica, com vistas a uma atuação mais qualificada.

É essencial que haja modelos reflexivos e ações enfáticas, no âmbito das políticas públicas, para o enfrentamento das práticas de combate ao racismo institucional, e a psicologia, enquanto profissão que se preocupa com as relações humanas, pode atuar como agente de transformação social no combate às manifestações de preconceito, intolerância e desrespeito aos direitos humanos. O cenário que se apresenta na saúde pública traz consigo demandas complexas, convocando a psicologia, com um conjunto de contribuições técnicas, estratégicas e procedimentais na construção de políticas públicas, reafirmando, nesse sentido, a relevância das psicólogas no enfrentamento das mais diversas demandas da sociedade.

Pretendeu-se dar visibilidade à temática e realizar uma aproximação das concepções e atuação dos profissionais, visando problematizar a invisibilidade do racismo, bem como refletir sobre a importância do tema e de uma atuação mais adequada.
Indaga-se e busca-se refletir: por que profissionais não conseguem observar o racismo nas instituições em que atuam? Ao se naturalizar a percepção, não se consegue perceber que o racismo se dá de diversas maneiras, não apenas de modo explícito.

Os entrevistados mencionam não ter em suas práticas um viés de enfrentamento do racismo nos espaços em que atuam; portanto, tornam-se necessárias atualizações, por meio de capacitações sobre temas que são fundamentais para atender à população de Salvador. Será imprescindível que outras pesquisas sejam realizadas para aprofundar os questionamentos que emergiram no âmbito da presente pesquisa.

\section{Informações sobre os autores:}

\section{Kaike Costa Oliveira de Jesus \\ (iD) https://orcid.org/0000-0001-8779-6862 \\ (9) http://lattes.cnpq.br/3206371413249182}

Graduado em Psicologia pela Escola Bahiana de Medicina e Saúde Pública - EBMSP.

\section{Hellen Maciel Santana \\ (iD) http://orcid.org/0000-0001-9349-0237 \\ (9) http://lattes.cnpq.br/9702230626350201}

Psicóloga pela Escola Bahiana de Medicina e Saúde Pública (EBMSP). Mestranda em Tecnologias em Saúde pela EBMSP (Bolsista CAPES). Participante do Grupo de Pesquisa: Psicologia, Diversidade e Saúde na linha de Pesquisa Memória, Cultura e Subjetividade. Realiza estudos e pesquisas na área de Psicologia Social e no campo da saúde. Atuação na Clínica de Psicologia da EBMSP. Pós-graduada na Especialização Lato Sensu em Gestalt-Terapia, promovida pelo Instituto de GestaltTerapia da Bahia (IGTBA).

\section{Marilda Castelar}

\section{(iD) https://orcid.org/0000-0003-1628-6739}

(9) http://lattes.cnpq.br/5770576514922680

Psicóloga, doutora em Psicologia Social e professora adjunta do Mestrado em Tecnologias em Saúde e do Mestrado Profissional em Psicologia e Intervenções em Saúde da Escola Bahiana de Medicina e Saúde Pública - EBMSP.

\section{Contribuições dos autores:}

Kaike Costa Oliveira de Jesus - participou de todas as etapas da pesquisa, sendo responsável pela concepção, desenho, análise, interpretação dos dados e escrita do artigo. Hellen Maciel Santana - como coautora, participou da interpretação dos dados e escrita do artigo. Marilda Castelar - como coautora, participou da orientação para a concepção, desenho e, posteriormente, da análise, interpretação dos dados e elaboração final do manuscrito. Todos os autores aprovaram a versão final do artigo.

\section{Como citar este artigo:}

\section{ABNT}

JESUS, Kaike Costa Oliveira de; SANTANA, Hellen Maciel; CASTELAR, Marilda. Psicologia e racismo institucional na saúde pública de Salvador- Bahia. Fractal: Revista de Psicologia, Niterói, v. 32, n. 2, p. 142-153, maio./ago. 2020. https://doi. org/10.22409/1984-0292/v32i2/5697

\section{APA}

Jesus, K. C. O., Santana, H. M., \& Castelar, M. (2020, Maio/ Agosto). Psicologia e racismo institucional na saúde pública de Salvador- Bahia. Fractal: Revista de Psicologia, 32(2), 142-153. doi: https://doi.org/10.22409/1984-0292/v32i2/5697 


\section{Copyright}

Copyright (C) 2020 Jesus, K. C. O., Santana, H. M., \& Castelar, M. Este é um artigo em acesso aberto distribuído nos termos da Licença Creative Commons Atribuição que permite o uso irrestrito, a distribuição e reprodução em qualquer meio desde que o artigo original seja devidamente citado.

Copyright (C) 2020 Jesus, K. C. O., Santana, H. M., \& Castelar, M. This is an Open Access article distributed under the terms of the Creative Commons Attribution License, which permits unrestricted use, distribution, and reproduction in any medium, provided the original article is properly cited.

\section{Referências}

BAHIA. Governo do Estado. Secretaria de Saúde. Diretoria de Gestão do Cuidado. Programa de combate ao racismo institucional (PCRI). Disponível em: http://www.saude.ba.gov. br/atencao-a-saude/saude-de-todos-nos/programa-de-combateao-racismo-institucional-pcri/. Acesso em: 15 jun. 2016.

BARDIN, Laurence. Análise de conteúdo. Lisboa, Portugal: Edições 70, 2009.

BOCK, Ana Mercês Bahia (Org.). Psicologia e ideologia: 40 anos de compromisso com as elites. In: Psicologia e compromisso social. 2. ed. São Paulo: Cortez, 2009. p. 15-28.

BRASIL. Lei ${ }^{\circ} 10.639$, de 9 de janeiro de 2003. Altera a Lei no 9.394, de 20 de dezembro de 1996, que estabelece as diretrizes e bases da educação nacional, para incluir no currículo oficial da Rede de Ensino a obrigatoriedade da temática "História e Cultura Afro-Brasileira", e dá outras providências. Diário Oficial União, Brasília, DF, 2003. Disponível em: http://www. planalto.gov.br/ccivil_03/leis/2003/L10.639.htm. Acesso em: 1 jul. 2015.

BRASIL. Programa das Nações Unidas para o Desenvolvimento. Programa de combate ao racismo institucional no Brasil. Brasília, 2005. Disponível em: http://www.saude.sp.gov.br/ resources/ses/perfil/profissional-da-saude/grupo-tecnico-deacoes-estrategicas-gtae/saude-da-populacao-negra/artigos-eteses/boletim_eletronico_marabr_-_2005.pdf. Acesso em: 15 jun. 2016.

CARNEIRO, Sueli. Mulheres em movimento. Estudos avançados, São Paulo, v. 17, n. 49, p. 117-133, 2003. https:// doi.org/10.1590/S0103-40142003000300008

CONSELHO FEDERAL DE PSICOLOGIA. CREPOP. Centro de Estudos de Administração Pública e Governo da Escola de Administração de Empresas de São Paulo da Fundação Getúlio Vargas. Documento relatório preliminar de análise qualitativa dos dados da pesquisa sobre a atuação dos/as psicólogos/as no CREAS e outros serviços especiais de acolhida e atendimento domiciliar do SUAS. São Paulo: CFP, 2009.

DOMINGUES, Petrônio. O mito da democracia racial e a mestiçagem no Brasil(1989-1930). Diálogos Latinoamericanos, n. 10: Universidad de Aarhus, p. 116-131, 2005. Disponível em: https://www.redalyc.org/pdf/162/16201007.pdf. Acesso em: 26 ago. 2015 .

FERREIRA, Ricardo Frankllin; CAMARGO, Amilton Carlos. As relações cotidianas e a construção da identidade negra. Psicologia: Ciência e Profissão, Brasília, v. 31, n. 2, p. 374 389, 2011. https://doi.org/10.1590/S1414-98932011000200013
GELEDÉS. Instituto da mulher negra; CFEMEA. Centro feminista de estudos e assessoria. Guia de Enfrentamento do Racismo Institucional, 2013. Disponível em: https://www. geledes.org.br/wp-content/uploads/2013/05/FINAL-WEBGuia-de-enfrentamento-ao-racismo-institucional.pdf. Acesso em: 17 out. 2016.

GESSER, Marivete. Políticas públicas e direitos humanos: desafios à atuação do psicólogo. Psicologia: Ciência e Profissão, Brasília, v. 33, n. spe, p. 66-77, 2013. Disponível em: http:// www.scielo.br/scielo.php?script=sci_arttext\&pid=S1414$98932013000500008 \& \operatorname{lng}=\mathrm{en} \& n r m=$ iso. Acesso em: 12 abr. 2020.

GONÇALVES, Maria da Graça Marchina. Psicologia, subjetividade e políticas públicas. São Paulo: Cortez, 2010.

INSTITUTO DE PESQUISA ECONÔMICA APLICADA (IPEA). Retrato das desigualdades de gênero e raça. 4. ed. Brasília: IPEA, 2011. Disponível em: https://www.ipea.gov.br/ retrato/pdf/revista.pdf. Acesso em: 9 dez. 2015.

LHUULLIER, Louise Amaral; Jessica J. Roslindo. As psicólogas brasileiras: levantando a ponta do véu. In: LHUULLIER, Louise Amaral (Org.). Quem é a psicóloga brasileira? Mulher, psicologia e trabalho. Brasília: CFP, 2013. p. 19-52. Disponível em: http://site.cfp.org.br/publicacao/ quem-e-a-psicologa-brasileira. Acesso em: 9 dez. 2015.

LIMA, Mônica. Atuação psicológica coletiva: uma trajetória profissional em unidade básica de saúde. Psicologia em estudo, Maringá, v. 10, n. 3, p. 431-440, 2005. Acesso em: 15 abr. 2009. https://doi.org/10.1590/S1413-73722005000300011

LIMA, Kênia Raisse Borges; SILVA, Juliana Alexandre da; PEREIRA, Lucilene Alves. Uma análise sobre a política pública de saúde no Brasil: enfatizando o contexto neoliberal. Políticas Públicas, 2015. Disponível em: http:// evelizabarbosapoliticaspublicas.blogspot.com/2015/01/ politica-publica-de-saude-no-brasil.html. Acesso em: 21 jun. 2016.

LÓPEZ, Laura Cecilia. O conceito de racismo institucional: aplicações no campo da saúde. Interface (Botucatu), Botucatu, v. 16 , n. 40 , p. 121-134, 2012. https://doi.org/10.1590/S141432832012005000004

MATOS, Aécio Gomes de. Alienação no serviço público. Revista Ciência e Profissão, Brasília, v. 14, n. 1-3, p. 28-33, 1994. https://doi.org/10.1590/S1414-98931994000100006

MEIHY, José Carlos Sebe Bom; RIBEIRO, Suzana Lopes Salgado. Guia prático de história oral: para empresas, universidades, comunidades, famílias. São Paulo: Contexto, 2011.

MINAYO, Maria Cecília de Souza. O desafio do conhecimento: pesquisa qualitativa em saúde. 12. ed. São Paulo: Hucitec, 2010.

MUNANGA, Kabengele. Adifícil tarefa de definir quem é negro no Brasil. Estudos Avançados, São Paulo, v. 18, n. 50, p. 51-66, 2004. https://doi.org/10.1590/S0103-40142004000100005

NOGUEIRA, Isildinha Baptista. O Corpo da Mulher Negra. Pulsional Revista de Psicanálise, ano 13, n. 135, p. 40-45, 1999. Disponível em: https://negrasoulblog.files.wordpress. com/2016/04/o-corpo-da-mulher-negra-isildinha-b-nogueira. pdf. Acesso em: 20 dez. 2019. 
RIBEIRO, Mara Cristina; MACHADO, Ana Lúcia. O uso do método história oral nas pesquisas qualitativas: contribuições para a temática do cuidado em saúde mental. Estudos e Pesquisas em Psicologia, Rio de Janeiro, v. 14, n. 2, p. 578591, 2014. Disponível em: http://pepsic.bvsalud.org/scielo. php?script=sci_arttext\&pid=S1808-42812014000200011\&lng =es\&nrm=iso. Acesso em: 15 dez. 2019.

SANTOS, Mafoane Odara Poli. Médicos e pacientes têm sexo e cor? A perspectiva de médicos sobre a relação médico-paciente na prática ambulatorial. 2012. Dissertação (Mestrado em Psicologia Social) - Instituto de Psicologia, Universidade de São Paulo, São Paulo, 2012. https://doi.org/10.11606/D.47.2012. tde-05092012-101342

SCHUCMAN, Lia Vainer. Entre o "encardido", o "branco" e o "branquíssimo": raça, hierarquia e poder na construção da branquitude paulistana. Tese (Doutorado em Psicologia Social) - Instituto de Psicologia, Universidade de São Paulo, São Paulo, 2012. https://doi.org/10.11606/T.47.2012.tde21052012-154521

SILVA, Josenilton Marques da et al. A promoção à igualdade racial em 2006 e o Programa de Combate ao Racismo Institucional. In: JACCOUD, Luciana de Barros (Org.). A construção de uma política de promoção da igualdade racial: uma análise dos últimos vinte anos. Brasília: IPEA, 2009. p. 147-170. Disponível em: https://pesquisa.bvsalud.org/portal/ resource/pt/biblio-1047704. Acesso em: 26 ago. 2016.

SOUZA, Celina. Politicas públicas: conceitos, tipologias e subáreas. Trabalho elaborado para a Fundação Luís Eduardo Magalhães. São Paulo, 2002.

SOUZA, Celina. Políticas públicas: uma revisão da literatura. Sociologias, Porto Alegre, n. 16, p. 20-45, 2006. https://doi. org/10.1590/S1517-45222006000200003

SUAREZ, Mireya; BANDEIRA, Lourdes. A politização da violência contra a mulher e o fortalecimento da cidadania. In: BRUSCHINI, Cristina; UNBEHAUM, Sandra Gouretti. (Org.). Gênero, democracia e sociedade brasileira. São Paulo: Fundação Carlos Chagas/Editora 34, 2002. p. 307-309. 